\title{
Erciyes Üniversitesi Tıp Fakültesi Öğrencilerinde Akıllı Telefon Bağımlılığı ile Akademik Erteleme ve Akademik Başarı Arasındaki İlişki
}

\section{The Relationship Between Smart Phone Addiction and Academic Procrastination and Academic Success in Erciyes University Medical Faculty Students}

\author{
Zeynep BAYKAN* (ORCID: 0000-0001-9450-985X) \\ Hasan GÜNEŞ* (ORCID: 0000-0001-7990-8326) \\ Mevlüde Yasemin AKŞEHIRLI SEYFELI' (ORCID: 0000-0002-7492-7891) \\ *Erciyes Üniversitesi Tıp Fakültesi Kayseri, TÜRKIYE \\ Sorumlu Yazar: Zeynep BAYKAN, E-Posta: zbaykan@ erciyes.edu.tr
}

\section{Özet}

Amaç: İnternet ve akıllı telefonların günlük hayata getirdikleri kolaylıklar yanında bilinçsiz kullanımları birtakım sorunları da beraberinde getirmektedir. Bu çalışmada Erciyes Üniversitesi Tıp Fakültesi öğrencilerinde akıllı telefon bağımlılık oranlarını, akademik erteleme düzeylerini, akıllı telefon kullanım özelliklerini belirlemek ve nomofobi ile akademik erteleme ve akademik başarı arasındaki ilişkiyi incelemek amaçlanmıştır.

Yöntem: Çalışma da her bir sınıf için en az 75 öğrencinin örneklem grubuna alınması gerektiği hesaplanmış; toplam 450 öğrenciye ulaşılması hedeflenmiş ve 511 öğrenciye ulaşılmıştır. Çalışma için gerekli etik kurul izni ve dekanlık izni alınmıştır. Tarama yöntemi kullanılmıştır. Veri toplama araçları anket, öğrencilerin sosyodemografik ve akıllı telefon kullanım özelliklerini soran sorularla akıllı telefon

Anahtar sözcükler:

Tıp, Öğrenci, Akıllı

Telefon Bağımlılı̆̆ı,

Başarı, Erteleme

Keywords: Medicine, Student, Smartphone Addiction, Success,

Procrastination

Gönderilme Tarihi

Submitted: 29.12.2020

Kabul Tarihi

Accepted: 17.06.2021 bağımlılığ1 (nomofobi) ölçeği ve akademik erteleme ölçeğinden oluşmuştur. Ki kare, Kruskal Wallis varyans analizi, Mann Whitney U testi, pearson korelasyon analizi yapılmıştır. Nomofobi, akademik erteleme ve Genel Akademik Not Ortalaması arasındaki ilişkiler yapısal eşitlik modellemesi ile test edilmiştir.

Bulgular: Öğrencilerin \%99,8'i akıllı telefona sahipti. Öğrenciler akıllı telefonlarını en çok aileleri ile konuşmak ve sosyal ağlara girmek için kullanmaktadır. Nomofobi ölçeğinden alınan puan ortalamaları 70.1 25.1 (min:20-max:140) olarak hesaplanmıştır. İki öğrenci bağımlılık yok; 170 öğrenci $(\% 33,7)$ hafif düzeyde, 273 öğrenci $(\% 54,1)$ orta düzeyde ve 60 öğrenci $(\% 11,9)$ ciddi düzeyde bağımlı olarak değerlendirilmiştir. Öğrencilerin cinsiyetleri ile nomofobi düzeyleri arasında istatistiksel olarak anlamlı bir fark saptanmıştır. Kadınlarda ciddi düzeyde bağımlılık erkeklerden daha yüksek düzeyde tespit edilmiştir. Öğrencilerin akademik

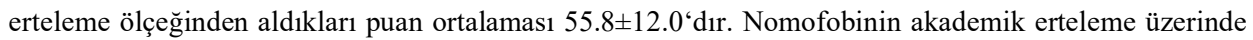
pozitif yönlü; akademik ertelemenin de GANO üzerinde negatif yönlü etkisi olduğu görülmüştür.

Künye: Baykan Z, Güneş H, Akşehirli Seyfeli MY. Erciyes Üniversitesi Tıp Fakültesi Öğrencilerinde Akıllı Telefon Bă̆ımlılı̆̆ ile Akademik Erteleme ve Akademik Başarı Arasındaki İlişki Tip Egitimi Dunvasi. 2021;20(61):119-134 
Nomofobinin genel akademik not ortalaması üzerinde negatif yönlü etkisi görüldü. Yapılan analizler birlikte incelendiğinde akademik ertelemenin genel akademik not ortalamasını düşürdüğ̈̈; nomofobin in doğrudan akademik ertelemeyi arttırırken dolaylı olarak da genel akademik not ortalamasını düşürdüğü belirlenmiştir.

Sonuç: Akıllı telefon kullanımı fakültemiz öğrencilerinde yaygındır ve akademik ertelemeye sebep olarak öğrenci başarısını da düşürmektedir.

\begin{abstract}
Aim: In addition to the convenience that the internet and smart phones bring to daily life, their unconscious use also brings some problems. It was aimed to determine the rates of smartphone addiction, academic procrastination, smartphone usage characteristics in Erciyes University Faculty of Medicine students and also to examine the relationship between nomophobia and academic procrastination and academic achievement.
\end{abstract}

Methods: 75 students from each class, 450 students were targeted, and 511 students were reached. The necessary ethics committee permission and dean's permission were obtained for the study. The survey method was used. The questionnaire consists of a smartphone addiction (nomophobia) scale and an academic procrastination scale with questions asking sociodemographic and smartphone usage characteristics. Chi square, Kruskal Wallis variance analysis, Mann Whitney U test, Pearson correlation analysis were performed. Relationships between nomophobia, academic procrastination and grade point average were tested by structural equation modeling.

Results: $99.8 \%$ of the students had a smartphone. Students mostly used their smartphones to talk to their families and to access social networks. Mean score for the nomophobia scale was calculated as $70.1 \pm$ 25.1 (min: 20-max: 140). Two students have no addiction; 170 students (33.7\%) were evaluated as mild, 273 students $(54.1 \%)$ as moderate and 60 students (11.9\%) as severely dependent. A statistically significant difference was found between the gender and nomophobia levels of the students. Severe addiction was found higher in women than men. The average score the students got from the academic procrastination scale was $55.8 \pm 12.0$. Nomophobia has positive effect on academic procrastination and academic procrastination has negative effect on grade point average. A negative effect of nomophobia on grade point average was also observed. When the analyzes are examined together, it is seen that academic postponement decreases the grade point average and nomophobia directly increases academic procrastination and indirectly decreases grade point average.

Conclusions: The use of smart phones is also common among the students of our faculty, and it reduces student success by causing academic procrastination.

\title{
GíRIŞ
}

21. yüzyıl bilgi ve iletişim teknolojilerinin yüzyılıdır. Yeni nesil kablosuz iletişim araçlarının zaman içindeki gelişimi mobil telefonları en hızlı gelişen sektörlerden biri haline getirmiştir. İnternet kullanımı da başladığı andan itibaren teknolojinin gelişmesiyle birlikte tüm dünyada hızla yayılım göstermiş ve kısa sürede herkesin ilgi odağ 1 olmuştur. Özellikle bilgisayar ağı işlevi sağlayan iletişim sistemlerinin bulunduğu akıllı telefonlarla internetin birleşimi akıllı telefonları hayatın vazgeçilmezi haline getirmiş ve insan hayatını önemli derecede etkilemiştir. Akıllı Tıp Eğitimi Dünyası / Mayıs-Ağustos 2021 / Say1 61 telefonlar artık sadece "cep telefonu" olarak değil gerçek zamanlı bilgi sağlayıcıları ve güçlü birer taşınabilir bilgisayarlar olarak kabul edilmektedir. Günümüzde akıllı telefonlar çok çeşitli özelliklere sahiptir. $\mathrm{Bu}$ özellikleri nedeniyle de dünya çapında geniş bir pazara sahip olmuştur $(1,2)$. Türkiye'de yıllar içinde akıllı telefon satışının giderek arttığı ve üniversite öğrencilerinin önemli bir kullanıcı grubu olduğu görülmektedir (3).

İnternet ve akıllı telefonların günlük hayata getirdikleri kolaylıklar yanında bilinçsiz kullanımları birtakım sorunları da beraberinde 
getirmiştir. Baş-boyun ağrısı, göz ve uyku bozukluğu gibi sağlık problemleri oluşmaktadır. Sosyal medyanın takibi ve haberleşme için mesajların kullanılması nedeniyle yüz yüze iletişim azalmakta; sürekli telefonu kontrol etme isteği nedeniyle konsantrasyon bozukluğu gelişmektedir. Dikkat dağıtıcı olmasından dolayı evde, işyerinde, trafikte kazalara sebep olduğu gösterilmiştir (1). Bununla birlikte akıllı telefonun aşırı kullanımı, okula veya işe yönelik tutumda değişikliklere, psikolojik veya davranışsal sorunlara da yol açabilmektedir. Bağımlılık bilinçsiz kullanımın getirdiği sorunlardan biridir. Kişi bağımlısı olduğu etkinlikten haz almakta, günlük yaşamını da buna göre düzenlediği için eksikliğinde yaşamı olumsuz yönde etkilenmektedir. Akıllı telefon ve mobil internetten yoksun kalma korkusu "Nomofobi (no mobile phone phobia)" olarak adlandırılmaktadır. Kişi telefonu olmadığında rahatsızlık hissetmekte, endişe duymakta ve gergin olmaktadır. Bu terim ilk kez 2008 yılında ortaya atılmış ve yarattığı stres, kaygı ve endişenin boyutları ve hızla yayılmasına bakılarak Bragazzi ve Del Puente tarafindan DSM-V Tanı Ölçütleri Başvuru El Kitabı'na (Diagnostic and Statistical Manual of Mental Disorders-V) dâhil edilmesi teklif edilmiştir (4). Son yıllarda dünyada ve ülkemizde yapılan çalışmalar nomofobinin üniversite öğrencileri arasında yaygın olduğunu göstermektedir. (59).

Üniversite yaşamı gençlerin birçok farklı sorumluluğu üstlendiği mesleki ve sosyal alana hazırlanma sürecinde önemli bir yer tutmaktadır. Eğitim süreçlerinde öğrencilerin akademik olarak yerine getirmeleri gereken birçok farklı görev olmakta; ancak çoğu öğrenci bu görevleri çeşitli nedenlerle ertelemekte ve öğrenciler arasında akademik erteleme davranışı giderek de artmaktadır (10,11). Akademik erteleme ders bırakma, düşük akademik ortalama ya da okuldan atılma gibi olumsuz sonuçlara yol açabilmektedir $(12,13)$. Ülkemizde üniversite öğrencilerinde akademik erteleme nedenlerine yönelik yapılan araştırma sayısı sınırlıdır (14-17).

Bu çalışmada Erciyes Üniversitesi Tıp Fakültesi (EÜTF) öğrencilerinde akıllı telefon bağımlılık oranlarını, akademik erteleme düzeylerini, akıllı telefon kullanım özelliklerini belirlemek ve nomofobi ile akademik erteleme ve akademik başarı arasındaki ilişkiyi incelemek amaçlanmıştır.

\section{GEREÇ VE YÖNTEM}

Çalışmada Demir ve Kutlu'nun “İnternet Bağımlılığı, Akademik Erteleme ve Akademik Başarı Arasındaki İlişkiler" adlı çalışmasında ölçekler arasında saptanan korelasyon (rho=0.40) değeri referans alınmış; her bir sınıf için etki büyüklüğü 0.05 , alfa hatas 0.05 , çalışmanın gücü 0.95 olması koşulunda en az 75 er öğrencinin örneklem gruplarına alınması gerektiği hesaplanmıştır (18). Toplam 450 öğrenciye ulaşılması hedeflenmiş ve sonuçta 511 öğrenciye ulaşılmıştır. Çalışma için Erciyes Üniversitesi klinik araştırmalar etik kurulundan (Karar No:2018/140, Karar Tarihi:21.03.2018) ve Tıp Fakültesi Dekanlığından izin alınmıştır. Çalışmada tarama yöntemi kullanılmıştır. Veri toplama araçları; anket, öğrencilerin kişisel özellikleri, akıllı telefon kullanım özellikleri ve mobil telefon kullanımına bağlı subjektif semptomları belirleyen 42 soru ile akıllı telefon bağımlılı̆̆ (nomofobi) ve akademik erteleme ölçeklerinden oluşmuştur.

\section{Akıllı Telefon Bağımlılı̆̆ (Nomofobi) Ölçeği:} Bireylerin akıllı telefon bağımlılığını ölçmek için Yıldırım ve Correia tarafindan geliştirilmiştir (19). Ölçek Türkçe'ye uyarlanmıştır (9). Ölçek yedili Likert tipinde 20 maddeden oluşmaktadır. Ölçekten alınabilecek puanlar 20-140 arasındadır. Ölçekten alınan puan 20 ise bağımlılık olmadığı, 21-59 arasında ise düşük seviyede, 60-99 arasında ise orta düzeyde, 100 puan ve üstünde ise ciddi düzeyde bağımlılığın bulunduğu şeklinde yorumlanmaktadır. Türkçe'ye uyarlanmış ölçeğin güvenirlik katsayısı 92'dir. Ölçeğin, 
"bilgiye erişememe" (4 madde), "bağlantıyı kaybetme" (5 madde), "iletişime geçememe" (6 madde) ve "rahat hissedememe" (5 madde) olmak üzere dört alt boyutu bulunmaktadır. Alt boyutların güvenirlik katsayıları ise sırasıyla .90, .74, .94 ve .91'dir. Yapılan bu araştırmada ölçeğin güvenirlik katsayısı .935, alt boyutların güvenirlik katsayıları sırasıyla .86, .82, .94 ve. 91 olarak bulunmuştur.

\section{Akademik Erteleme Ölçeği: Öğrencilerin} öğrenim yaşantılarında yapmaları gereken görevleri içeren (ders çalışma, sınavlara hazırlanma, proje hazırlama gibi) on iki olumsuz, yedi olumlu olmak üzere toplam 19 maddeden oluşmaktadır. Bu ölçekte yer alan maddelere verilen tepkiler beş basamaklı Likert tipinde derecelendirilmektedir (beni hiç yansitmiyor 1 puan, beni tamamen yansitiyor 5 puan olacak şekilde). Alınabilecek en düşük puan 19, en yüksek puan 95'tir. Ölçekten alınan yüksek puan, öğrencilerin akademik ertelemeci olduklarını göstermektedir. Ölçeğin Cronbach alpha güvenirlik katsayısı. 92 olarak bulunmuştur (20). Yapılan bu araştırmada ölçeğin güvenirlik katsayısı ise. 86'dır. Çalışmada 87 öğrenci okul numaralarını

\section{BULGULAR}

Araştırmada 511 tıp fakültesi öğrencisine ulaşılmıştır. Öğrencilerin yaş ortalaması 21.8 \pm 2.5 (min:18-max:38) y1lır. \%98,2'si bekardır. Araştırmaya katılan öğrencilerin sosyodemografik özellikleri Tablo 1'de gösterilmiştir.

Araştırmaya katılan öğrencilerden sadece biri akıllı telefona sahip değildir $(n=510)$. Sahip olan öğrencilerin tamamı akıllı telefonlarından internete bağlanmaktadır. Öğrencilerin $\% 68,0$ 'ının ak1llı telefonu 1000-3000 TL arasındadır. Akıllı telefon kullanımlarına ilişsin bulgular Tablo 2'de gösterilmiştir.

Öğrencilerin $\% 58,8^{\prime} \mathrm{i}$ akıllı telefonlarında medikal aplikasyonların yüklü olduğunu söylemiştir. Tablo 3'te öğrencilerin akıllı telefon kullanımlarına yönelik verilen belirtmedikleri için GANO'larına (Genel Akademik Not Ortalaması- öğrencilerin içinde bulundukları lisans dönemine kadar olan notlarının ortalaması) ulaşılamamıştır. Elde edilen veriler bilgisayara girilmiş, tanımlayıcı istatistikler verilmiştir. Analizlerde SPSS 22.0 istatistik paket programı kullanılmıştır. Akademik erteleme ve nomofobi ölçek puanlarının normal dağılıma uygunluğu Kolmogrov Smirnov testi ve grafiklerle değerlendirilmiştir. Kategorik değişkenler arasındaki farkı belirlemek için ki kare analizi kullanılmıştır. Ölçek puanlarının normallik dağılımına göre ortalamalar arası farklar için Kruskal Wallis Varyans analizi ve Mann Whitney $U$ testi yapılmıştır. Öğrencilerde nomofobi, akademik erteleme ve akademik başarı arasında ilişkileri incelenirken pearson korelasyon analizi yapılmıştır. Nomofobi, akademik erteleme ve GANO arasındaki ilişkiler yapısal eşitlik modellemesi ile test edilmiştir. Değişkenlerin etkileşimine dayalı ilişkisel tarama modeli, ileriye dönük olası araştırmalara bir bakış açısı sağlayarak bilime katkı sağlamaktadır (21). Bu analizler için STATA istatistik programı kullanılmıştır.

önermelere katılma durumlarının yüzde dağ 1 llımı verilmiştir.

Öğrenciler akıllı telefonlarını en çok aileleri ile konuşmak $(\% 28,1)$ ve sosyal ağlara girmek $(\% 28,0)$ için kullanmaktadırlar. Geceleri cep telefonların 380 öğrenci kapatmadığını ifade etmiş ve bu öğrencilerin \%7,4'ü telefonunu yastığının altında, \%70,3'ü kolay ulaşabileceği yatağına yakın bir yerde, \%17,1'i kendine uzak ancak aynı odada bulundurduğunu söylemiştir. Öğrencilerin \%95,3’ü uyumadan önce ak1llı telefonları ile zaman geçirdiklerini, $\% 87,8$ 'i ise uyanır uyanmaz akıllı telefonlarını kontrol ettiklerini ifade etmiştir. 114 öğrenci günde birden fazla, 348 öğrenci ise her gün telefonunu şarj etmektedir. $160(\% 31,4)$ "akıllı telefonunuz olmadan kaç gün geçirebileceğinizi 
düşünüyorsunuz?" sorusunda "geçiremem" şeklinde cevap vermiştir.

Öğrencilerin \%64,3'ü yemek masasında, $\% 95,5$ 'i otobüste, $\% 82,7$ 'si derste, $\% 73,5$ 'i yürürken, $\% 60,6$ 's1 biri ile sohbet ederken, $\% 81,6$ 's1 sosyal ortamlarda arkadaşlarının yanında iken bile akıllı telefonlarını kullanma/kontrol etme ihtiyacı hissetmektedir.
Katılımcıların \%28,2'si karşıdan karşıya geçerken ve arabası olanların $\% 33,4$ 'ü araba kullanırken de akıllı telefonlarını kullanma/kontrol etme ihtiyac1 hissetmektedir. 23 ögrenci evde, okulda veya trafikte akılı telefon yüzünden dikkati dağılıp kaza geçirdiğini ifade etmiştir.

Tablo 1. Araştırmaya Katılan Öğrencilerin Sosyodemografik Özellikleri

\begin{tabular}{|c|c|c|}
\hline & Say1 & $\%$ \\
\hline \multicolumn{3}{|l|}{ Cinsiyet (n=509) } \\
\hline Erkek & 215 & 42.2 \\
\hline Kadın & 294 & 57.8 \\
\hline \multicolumn{3}{|l|}{ Sinıf $(n=511)$} \\
\hline 1 & 78 & 15.3 \\
\hline 2 & 87 & 17.0 \\
\hline 3 & 99 & 19.4 \\
\hline 4 & 78 & 15.3 \\
\hline 5 & 86 & 16.8 \\
\hline 6 & 83 & 16.2 \\
\hline \multicolumn{3}{|l|}{ Kalınan Yer $(n=509)$} \\
\hline Ailenin Yanı & 250 & 49.1 \\
\hline Akrabalarının Yanı & 3 & 0.6 \\
\hline Yurt & 121 & 23.7 \\
\hline Arkadaşları ile Evde & 93 & 18.3 \\
\hline Evde tek & 35 & 6.9 \\
\hline Diğer & 7 & 1.4 \\
\hline \multicolumn{3}{|c|}{ Ailenin Ortalama Aylık Geliri $(n=501)$} \\
\hline 1600 TL alt1 & 42 & 8.4 \\
\hline $1600-5100 \mathrm{TL}$ aras 1 & 296 & 59.1 \\
\hline 5100 TL üzeri & 163 & 32.5 \\
\hline \multicolumn{3}{|c|}{ Öğrencinin Ortalama Aylık Harcaması $(n=505)$} \\
\hline $1600 \mathrm{TL}$ alt1 & 459 & 90.9 \\
\hline $1600-5100 \mathrm{TL}$ aras 1 & 41 & 8.1 \\
\hline 5100 TL üzeri & 5 & 1.0 \\
\hline
\end{tabular}


Tablo 2. Araştırmaya Katılan Akıllı Telefon Kullanan Öğrencilerin Kullanımlarıyla İlgili Özellikleri

\begin{tabular}{|c|c|c|}
\hline & Sayı & $\%$ \\
\hline \multicolumn{3}{|c|}{ Akıllı Telefona Sahip Olma Süresi $(\mathrm{n}=508)$} \\
\hline$<1 \mathrm{y} 1 \mathrm{l}$ & 6 & 1.2 \\
\hline $1-3$ yil & 89 & 17.5 \\
\hline $4-6$ yil & 265 & 52.2 \\
\hline$>6$ y1l & 148 & 29.1 \\
\hline \multicolumn{3}{|c|}{ Akıllı Telefon Seçimindeki İlk Kriter $(n=507)$} \\
\hline Fonksiyon & 295 & 58.2 \\
\hline Marka & 117 & 23.1 \\
\hline Fiyat & 45 & 8.9 \\
\hline Görünüş & 31 & 6.1 \\
\hline Diğer & 19 & 3.7 \\
\hline \multicolumn{3}{|c|}{ Günlük Ortalama Akıllı Telefon Kullanma Süresi $(\mathrm{n}=510)$} \\
\hline$<1$ saat & 64 & 12.5 \\
\hline 1-4 saat & 324 & 63.5 \\
\hline$>4$ saat & 122 & 24.0 \\
\hline \multicolumn{3}{|c|}{ Akıllı Telefon Kontrol Etme Sıklığı (n=506) } \\
\hline Her 5-20 dakikada bir & 130 & 25.7 \\
\hline 21-40 dakikada bir & 190 & 37.5 \\
\hline 41-60 dakikada bir & 121 & 23.9 \\
\hline 60 dakika üzerinde & 65 & 12.9 \\
\hline
\end{tabular}

Tablo 3: Öğrencilerin Verilen Önermelere Katılım Durumları (\%)

\begin{tabular}{|c|c|c|c|c|c|}
\hline & $\begin{array}{c}\text { Evet, } \\
\text { her } \\
\text { zaman }\end{array}$ & $\begin{array}{l}\text { Evet, } \\
\text { Sıklıkla }\end{array}$ & $\begin{array}{l}\text { Evet, } \\
\text { bazen }\end{array}$ & $\begin{array}{c}\text { Evet, } \\
\text { nadiren }\end{array}$ & Hayır \\
\hline $\begin{array}{l}\text { Ders çalışırken mobil telefonunu yanında } \\
\text { bulundurma }(n=509)\end{array}$ & 29.3 & 42.4 & 18.9 & 4.9 & 4.5 \\
\hline $\begin{array}{l}\text { Ders çalışırken sosyal medyayı kontrol etme } \\
(\mathrm{n}=510)\end{array}$ & 12.7 & 21.4 & 33.1 & 17.1 & 15.7 \\
\hline $\begin{array}{l}\text { Teorik dersler sırasında telefonunu kapatma } \\
\text { (uçak modu dahil) }(n=510)\end{array}$ & 4.3 & 4.3 & 6.9 & 9.8 & 74.7 \\
\hline $\begin{array}{l}\text { Pratik dersler sırasında telefonunu kapatma } \\
\text { (uçak modu dahil) }(\mathrm{n}=507)\end{array}$ & 4.3 & 7.9 & 6.7 & 9.9 & 71.2 \\
\hline $\begin{array}{l}\text { Teorik dersler sirasinda telefonunu kontrol } \\
\text { etme }(n=510)\end{array}$ & 9.8 & 21.6 & 35.7 & 20.4 & 12.5 \\
\hline Bildirimlere cevap verme $(\mathrm{n}=510)$ & 9.2 & 23.3 & 31.8 & 19.2 & 16.5 \\
\hline $\begin{array}{l}\text { Pratik dersler sırasinda cep telefonunu kontrol } \\
\text { etme }(n=507)\end{array}$ & 4.5 & 14.6 & 29.6 & 27.6 & 23.7 \\
\hline Bildirimlere cevap verme $(n=507)$ & 5.7 & 15.0 & 27.8 & 20.5 & 31.0 \\
\hline Dersler sırasında oyun oynama $(\mathrm{n}=509)$ & 2.9 & 5.9 & 18.7 & 16.3 & 56.2 \\
\hline $\begin{array}{l}\text { Teorik ders sırasında çalan telefonu cevaplama } \\
(\mathrm{n}=510)\end{array}$ & 1.3 & 0.8 & 6.3 & 10.4 & 81.2 \\
\hline $\begin{array}{l}\text { Pratik ders sırasında çalan telefonu cevaplama } \\
(\mathrm{n}=506)\end{array}$ & 1.4 & 2.2 & 5.5 & 9.1 & 81.8 \\
\hline $\begin{array}{l}\text { Ders çalışırken çalan telefonu cevaplama } \\
(\mathrm{n}=508)\end{array}$ & 23.0 & 35.2 & 18.1 & 10.4 & 13.3 \\
\hline
\end{tabular}


Öğrencilerin akıllı telefon kullanımının kendilerinde yarattığını etkilere ilişkin düşünceleri Tablo 4'te gösterilmiştir.

Ak1llı telefonu olan 510 öğrenciden 505 öğrenci nomofobi ölçeğini eksiksiz olarak doldurmuştur. $\mathrm{Bu}$ öğrencilerin ölçek puan ortalamalar1 70.1 \pm 25.1 'dir (min:20-max:140). Akıllı telefonu olan öğrencilerin ikisinin puanı $(\% 0,4) \quad 20$ 'dir ve bağımlılık yok olarak değerlendirilmiştir. \%33,7'si (n=170) hafif düzeyde, $\% 54,1$ 'i $(\mathrm{n}=273)$ orta düzeyde ve $\% 11,9$ 'u (n=60) ciddi düzeyde bağımlılık göstermektedir. Öğrencilerin alt boyutlardan aldıkları puan ortalamaları bilgiye

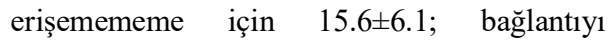

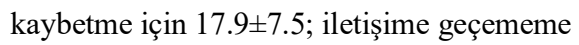

için 23.8 \pm 9.9 ; rahat hissedememe için $12.7 \pm 7,8$ olarak hesaplanmıştır. Kendisini akıllı telefon bağımlısı olarak nitelendirmeyen 331 öğrencinin \%41,4'ü hafif, \%52,3'ü orta ve $\% 5,7$ 'si ciddi düzeyde bağımlı olarak tespit edilmiştir.

Öğrencilerin cinsiyetleri ile nomofobi düzeyleri arasında istatistiksel olarak anlamlı bir fark saptanmıştır (ki kare=8.042; p=0.045). Fark ciddi bağımlılık düzeyinde olmuştur. Kadınların \%14,8'i ciddi düzeyde bağımlı iken erkeklerin $\% 8,0$ 'i ciddi düzeyde bağımlı olarak tespit edilmiştir. Öğrencilerin sınıfları ile nomofobi düzeyleri arasında istatistiksel olarak anlamlı bir fark bulunmamışır (ki kare $=20.288$ $\mathrm{p}=0.161$ ).

Tablo 4. Öğrencilerin Akıllı Telefon Kullanımının Kendilerinde Yarattığı Etkilere İlişkin Düşüncelerinin Dağılımı (\%)

\begin{tabular}{lcc}
\hline Etkiler & Evet & Hayır \\
\hline Göz yorgunluğu /bozukluğu $(\mathrm{n}=507)$ & 75.7 & 24.3 \\
\hline Konsantrasyon bozukluğu $(\mathrm{n}=504)$ & 53.4 & 46.6 \\
\hline Uyku bozukluğu (n=508) & 49.2 & 50.8 \\
\hline Yorgunluk/ uyuşukluk (n=507) & 48.7 & 51.3 \\
\hline Baş ağrısı (n=504) & 43.8 & 56.2 \\
\hline Parmaklarda uyuşma (n=507) & 39.3 & 60.7 \\
\hline Bileklerde ya da boyunda ağrı (n=507) & 39.1 & 60.9 \\
\hline Akademik başarıda düşme $(\mathrm{n}=503)$ & 35.4 & 64.6 \\
\hline Sabırsızlık (n=505) & 33.0 & 67.0 \\
\hline Sosyal etkileşimde azalma (n=503) & 33.0 & 67.0 \\
\hline Kulak ağrı1 (n=503) & 14.9 & 85.1 \\
\hline Duymada zorluk (n=504) & 11.7 & 88.3
\end{tabular}

Öğrencilerin akademik erteleme ölçeğinden aldıkları puan ortalamas1 $55.8 \pm 12.0^{\circ} \mathrm{d}$ ır (ortanca $=56.0$ ). Bazı özelliklere göre akademik erteleme puanlarının dağılımı Tablo 5'te gösterilmiştir.

Sınıf, nomofobi durumu, öğrencinin okuldaki akademik başarısını değerlendirme durumu ile akademik erteleme puanları arasında istatistiksel olarak anlamlı fark bulunmuştur.
Öğrencilerde nomofobi, akademik erteleme ve akademik başarı arasında ilişki Tablo 6'da gösterilmiştir.

Akademik erteleme ile GANO arasında negatif yönlü orta düzey bir korelasyon ve nomofobi ile akademik erteleme arasında pozitif yönlü düşük bir korelasyon saptanmıştır. 
Tablo 5. Bazı Özelliklere Göre Akademik Erteleme Puanlarının Dağılımı

\begin{tabular}{|c|c|c|}
\hline Özellikler & $\begin{array}{l}\text { Akademik erteleme puan } \\
\text { Ortanca (min-max) }\end{array}$ & $\mathbf{p}$ \\
\hline \multicolumn{3}{|l|}{ Cinsiyet } \\
\hline Erkek & $56.0(31.0-93.0)$ & \\
\hline Kadın & $56.0(23.0-91.0)$ & $p=0.635$ \\
\hline \multicolumn{3}{|l|}{ Sinıf } \\
\hline 1 & $57.0(23.0-82.0)^{\mathrm{ab}}$ & \\
\hline 2 & $55.0(34.0-91.0)^{\mathrm{ab}}$ & \\
\hline 3 & $55.0(29.0-81.0)^{\mathrm{ab}}$ & \\
\hline 4 & $52.0(27.0-92.0)^{\mathrm{a}}$ & \\
\hline 5 & $59.0(33.0-93.0)^{\mathrm{b}}$ & \\
\hline 6 & $55.0(31.0-81.0)^{\mathrm{ab}}$ & $p=0.046$ \\
\hline \multicolumn{3}{|c|}{ Nomofobi durumu } \\
\hline Yok & $46.5(46.0-47.0)^{\mathrm{abc}}$ & \\
\hline Hafif & $53.05(29.0-93.0)^{\mathrm{a}}$ & \\
\hline Orta & $57.0(23.0-91.0)^{\mathrm{bc}}$ & \\
\hline Ciddi & $58.0(34.0-92.0)^{\mathrm{c}}$ & $p=0.023$ \\
\hline \multicolumn{3}{|c|}{$\begin{array}{l}\text { Okuldaki akademik başarı durumunu } \\
\text { nasıl değerlendirdiği }\end{array}$} \\
\hline Çok iyi & $23.0(23.0-67.0)^{\text {ade }}$ & \\
\hline İyi & $49.0(27.0-82.0)^{\mathrm{d}}$ & \\
\hline Orta & $57.0(31.0-90.0)^{\mathrm{e}}$ & \\
\hline Kötü & $64.0(37.0-83.0)^{\mathrm{b}}$ & \\
\hline Çok kötü & $76.0(54.0-93.0)^{\mathrm{bc}}$ & $p<0.001$ \\
\hline
\end{tabular}

Aynı harfleri içerenler benzer gruplardır.

Tablo 6: Nomofobi, Akademik Erteleme ve Akademik Başarı Arasında İlişki

\begin{tabular}{lccc}
\hline & Nomofobi & Akademik erteleme & GANO \\
\hline Nomofobi & 1 & & \\
\hline Akademik erteleme & $0,178^{*}$ & 1 & \\
\hline GANO & 0,16 & $-0,314^{*}$ & 1 \\
\hline
\end{tabular}

$* \mathrm{p}<.05$ 
Nomofobi, akademik erteleme ve GANO Nomofobi, akademik erteleme ve GANO'ya arasındaki ilişkilerin yapısal eşitlik ilişkin hipotetik model path analizi sonuçları modellemesi;

Şekil 1'de gösterilmiştir.

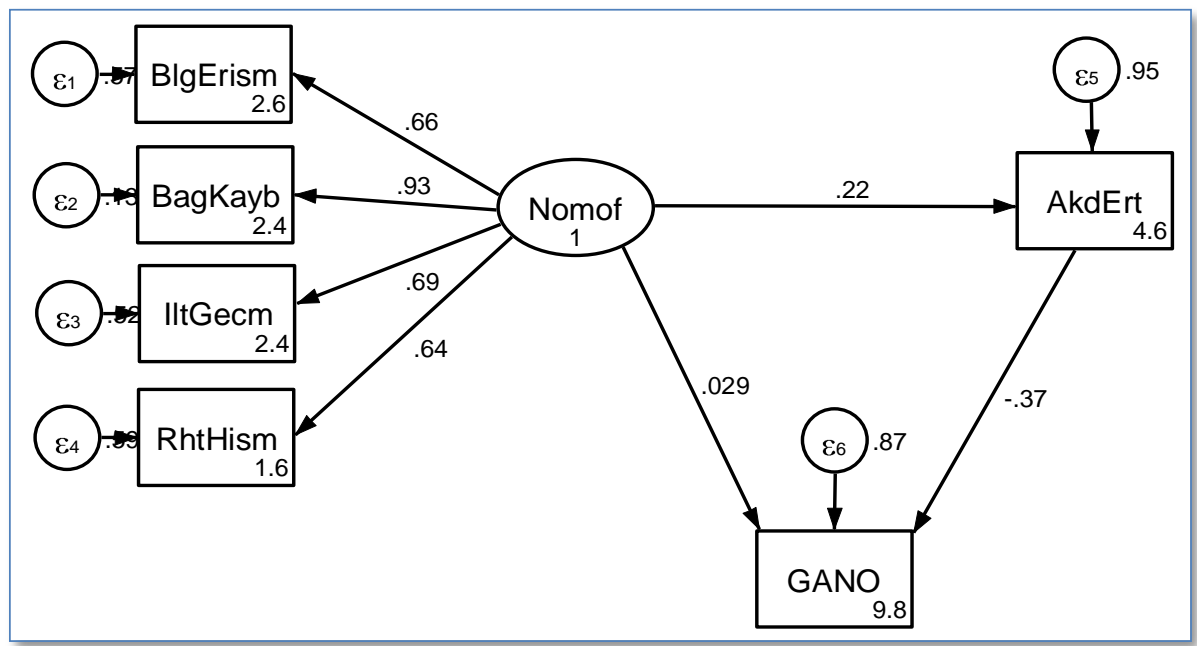

Şekil 1. Nomofobi, Akademik Erteleme ve GANO‘ya İlişkin Hipotetik Model Path Analizi

Hipotetik modele ilişkin uyum indeksleri incelenmiş ve modelin $\mathrm{x} 2 / \mathrm{sd}$ si 1,31 olarak hesaplanmıştır. Modelde RMSEA: 0.027, GFI: 0.98, TLI: 0.99 , IFI: 0.99 ve CFI değeri ise 0.99 'dur. Modelde yer alan yolların tamamı 0.001 düzeyinde anlamlıdır. SRMR değeri ise $0.022^{\prime}$ dir. RMSEA değerinin .80 'in altında olmas1, x2/sd'nin 5'ten küçük olması ve GFI, TLI, IFI, AGFI ve CFI değerlerinin ise .90 ' 1 n üzerinde olması modelin iyi uyumunu göstermiştir. $\mathrm{Bu}$ bulgular birlikte değerlendirildiğinde, değerlerin oluşturulan hipotetik modeli doğrulandığı söylenir. Kabul ettiğimiz hipotetik modelin regresyon katsayıları Tablo 7'de gösterilmiştir. Hipotetik modelin regresyon katsayıları incelendiğinde; nomofobinin akademik erteleme üzerinde pozitif yönlü, akademik ertelemenin de GANO üzerinde negatif yönlü etkisi olduğu görülmüştür. Nomofobinin GANO üzerinde negatif yönlü etkisi de görülmektedir.

Yapılan tüm analizler birlikte incelendiğinde akademik ertelemenin GANO'yu düşürdüğü; nomofobinin doğrudan akademik ertelemeyi arttırırken dolaylı olarak da GANO'yu düşürdüğü gösterilmiştir.

Tablo 7. Hipotetik Modelin Regresyon Katsayıları

\begin{tabular}{llcccc}
\hline & & $\begin{array}{c}\text { Katsayı/ } \\
\text { standardize } \\
\text { katsayı }\end{array}$ & $\begin{array}{c}\text { Standart } \\
\text { hata }\end{array}$ & $\mathbf{z}$ & $\mathbf{p}$ \\
\hline \multirow{2}{*}{$\begin{array}{l}\text { Doğrudan } \\
\text { etkiler }\end{array}$} & Nomofobi akademik $\rightarrow$ erteleme & $0.666 / 0.216$ & 0.160 & 4.14 & $<\mathbf{0 . 0 0 1}$ \\
\cline { 2 - 6 } & Akademik erteleme $\rightarrow$ GANO & $-0.011 /-0.372$ & 0.001 & -7.98 & $<\mathbf{0 . 0 0 1}$ \\
\cline { 2 - 6 } Domofobi $\rightarrow$ GANO & $0.003 / 0.03$ & 0.005 & 0.60 & 0.551 \\
\hline $\begin{array}{l}\text { Dolaylı } \\
\text { etki }\end{array}$ & Nomofobi $\rightarrow$ GANO & $-0.007 /-0.08$ & 0.002 & -3.67 & $<\mathbf{0 . 0 0 1}$ \\
\hline
\end{tabular}




\section{TARTIŞMA}

Çalışmamızda sadece bir öğrencinin akıllı telefona sahip olmadığı ve diğer öğrencilerin tamamının akıllı telefonlarından internete bağlandığı görülmüsstür. Akıllı telefona sahip olma oranı ülkemizde ve yurtdışında üniversite öğrencilerinde yapılan çalışmalarda \%90'ların üzerinde bulunmuştur (22-25). Bu durum akıllı telefonların üniversite öğrencilerinin hayatlarında vazgeçilmezler arasında yerini aldığını göstermektedir. Bunu destekleyen diğer bulgularımız da öğrencilerin üçte birinin telefonsuz gün geçiremeyeceğini söylemesi ve günlük işleri sırasında dahi akıllı telefonlarını kullanma/kontrol etme ihtiyacı hissetmeleridir. Diğer çalışmalarda da artık insanlar cep telefonsuz kalamayacaklarını söylemektedirler $(5,6)$. Öğrencilerin akıllı telefon seçimlerini etkileyen en önemli özellik bu çalışmada da diğer çalışmalardaki gibi akıllı telefonun fonksiyonu olmuştur $(7,26)$. Öğrencilerin yarıdan fazlasının akıllı telefonlarında medikal aplikasyonlar yüklüdür. $\mathrm{Bu}$ fonksiyonu ile telefonlarını eğitimleri için de kullandıklarını göstermektedir. Araştırmamızda öğrenciler akıllı telefonlarını en s1k aileleri ile konuşmak ve sosyal ağlara girmek için kullanmaktadırlar. Ülkemizde ve yurtdışında yapılan çalışmalarda benzer sonuçlar elde edilmiştir $(6,21,25-27)$. Öğrencilerimizin yarıdan fazlası akıllı telefonlarını günlük ortalama 1-4 saat arasında kullanmaktadır. Tıp öğrencilerinde öğrencilerin çoğunlukla günlük ortalama 1-4 saat aralığında akıllı telefonlarını kullandıklarını gösteren çalışmalar olduğu gibi $(25,28)$ bundan daha fazla saat telefonla zaman geçirdiklerini gösteren çalışmalar da bulunmaktadır $(22,24,29)$. Çalışmamızda dört öğrenciden birinin telefonunu her 5-20 dakikada bir kontrol etmesi; büyük kısmının telefonlarını ders çalışırken yanlarında bulundurması; sosyal medyayı kontrol etmesi, çalan telefonlara cevap vermesi hem teorik hem de pratik derslerde telefon bildirimlerine cevap vermesi diğer önemli bulgular olarak değerlendirilmiştir. Tip öğrencilerinde yapılan başka çalışmalarda da benzer bulgular elde edilmiştir $(24,30)$. Öğrencilerin derslerde telefonları kapatma yerine sessiz moda aldıkları ve bildirimlerden dolayı sınıfta yapılması gereken işler yerine başka işlere yöneldikleri gösterilmiştir. Sınıf içinde mobil teknolojilerin eğitim amaçlı kullanımında bile, öğrencilerin yaklaşık her beş dakikada bir öğrenmelerini verimli kılacak etkinliklerden; SMS, sohbet uygulamaları, ya da sosyal ağlarda gezinme gibi verimsiz işlere yöneldikleri ve bazı öğrencilerin bu görev geçişlerini yapamadan iki dakika bile duramadıkları tespit edilmiştir (31). Öğrencilerin ders sırasında veya ders çalışırken ak1llı telefonlarını kullanmalarının dikkatlerini dersten uzaklaştıracağı açıktır. Bizim çalışmamızda bunu destekleyen bir diğer bulgu öğrencilerimizin yaklaşık yarısının akıllı telefon kullanımının kendilerinde konsantrasyon bozukluğu yarattığını düşünmesidir. Yaklaşık üçte birinde de telefon kullanımının akademik başarılarında düşmeye neden olduğunu düşünmektedir. Aman'ın çalışmasında da tıp öğrencilerinin yarısı akademik performanslarının telefondan etkilendiğini belirtmiştir (30). Baghianimoghadam'ın çalışmasında da sağlık bilimleri öğrencilerin yaklaşık dörtte biri aynı şekilde cep telefonunun çalışmaları ve akademik başarıları üzerinde ciddi olumsuz etkileri olduğunu belirtmiştir (23). Dikkatin dersten uzaklaşması öğrencilerin bilişsel performanslarında düşüşe yol açmakta, ögrrenmenin verim ve kalitesini düşürmekte ve hatırlamayı zorlaştırmaktadır $(32,33)$.

Çalışmamızda öğrencilerin çok büyük bir bölümünün uyumadan önce akıllı telefonları ile zaman geçirdikleri belirlenmiştir. Üniversite öğrencilerinde yatmadan önce telefonla vakit geçirmek oldukça yaygındır. $\mathrm{Bu}$ oranın çalışmalarda \%90'ların üzerinde olduğu gösterilmiştir (25,34). Cep telefonlarına bakarken mavi ışığa maruz kaldıkları için uykusuzluk problemi çekmektedirler (1). Öğrencilerimizin yarısı telefon kullanımına bağlı uyku bozukluğu yaşadığını söylemektedir. Benzer şekilde birinci sınıf tıp öğrencilerinde 
yapılan çalışmada \%49,7'si cep telefonu nedeniyle uyku düzeninin bozulduğunu belirtmiştir (29). Uykusuzluk öğrencilerin eğitim hayatını etkileyen günlük işlerine konsantre olamamalarına hatta akademik erteleme davranışına yol açan bir faktör olabilir. Öğrencilerin yarıdan fazlası cep telefonu kullanım etkileri olarak göz yorgunluğu; yaklaşık yarısı yorgunluk/uyuşukluk ve baş ağrısını belirtmiştir. Bir başka çalışmada da baş ağrısı ve yorgunluk/uyuşukluk en sık yaşanan yan etkiler olarak belirtilmiştir (8).

Öğrencilerin \%33,9'u kendisini, \%14,1'i annesini, \%11,9'u babasını akıllı telefon bağımlısı olarak nitelendirmektedir. Ülkemizde tıp fakültesi birinci sınıf öğrencilerinde yapılan çalışmada kendisini telefon bağımlısı olarak niteleyen öğrencilerin oranı \%27,4 olarak bulunmuştur (29). Kardeşi/kardeşleri olanların $\% 46,5$ 'i kardeşi/kardeşlerini akıllı telefon bağımlısı olarak nitelendirmektedir. Bu da her geçen nesilde telefon bağımlılı̆̆ın arttığının bir göstergesi olarak düşünülebilir. Diğer ilginç bir bulgu da kendisini bağımlı olarak sınıflamayan öğrencilerin bağımlı olması yani durumlarını farkında olmamaları ve ögrencilerin kendilerinin bağımlı görmemelerine rağmen toplumumuzda akıllı telefon kullanımının bağımlılık düzeyinde olduğunu (\%94,7) düşünmesidir. Teknolojinin gün geçtikçe yaygınlaşması ve kontrolsüz ve bilinçsiz bir şekilde kullanılması sonucu akıllı telefon bağımlılığında artış beklenen bir durumdur. Ancak öğrencilerin nomofobinin tehlikelerinin ne kadar farkında olduklarının değerlendirilmesi ve yapılacak bilgilendirmelerle ciddi bağımlılık oluşmadan akılcı kullanımın sağlanması önemli görünmektedir.

2018 yılında yürüttüğg̈müz çalışmamızda EÜTF öğrencilerinin \%33,7'si hafif düzeyde, $\% 54,1$ 'i orta düzeyde ve $\% 11,9$ 'u ciddi düzeyde telefon bağımlısı olarak saptanmıştır. Tip öğrencilerinde yapılan araştırmalarda bağımlılığı tespit etmek için kullanılan testlere de bağlı olarak bağımlılık oranlarının değişkenlik gösterdiği görülmektedir. Oranlar $\% 14,6$ ile $\% 75$ arasında değişmektedir. (5,8,27,35-37). Çalışmamızda kullanılan ölçekle yapılan çalışmalarda ciddi bağımlılık \%3'ün altından \%7,5' e kadar bildirilmiştir $(27,28,38)$. Bizim çalışmamızda ciddi düzeyde bağımlılık bu çalışmalardan daha yüksek $(\% 11,9)$ düzeyde bulunmuştur. Birinci sınıf tıp öğrencilerinde yapılan bir başka çalışmada ise ciddi bağımlılık \%22,1, orta düzeyde bağımlılık $\% 60,0$ oranında tespit edilmiştir (34). Kültürel faktörler ve çalışmanın yürütüldüğü yıllar bunda etken olmuş olabilir.

Ülkemizde Sezer ve ark. ile Okuyan ve ark.'nın aynı ölçekle tıp fakültesi öğrencilerinde yaptıkları çalışmalarında ölçek puan ortalamaları sirasiyla $75.58 \quad \pm 23.70 \quad$ ve $77.2 \pm 22,4$ olarak hesaplanmıştır $(39,40)$. Çalışmamızda $70.1 \pm 25,1$ olarak bulunmuştur. Nomofobi ölçeğinin kullanıldığı diğer çalışmalarda olduğu gibi bizim çalışmamızda da iletişime geçilememe ve bilgiye erişememe faktörlerinin daha yüksek puanlar aldığ görülmektedir $(37,39,40)$.

Çalışmamızda öğrencilerin cinsiyetleri ile nomofobi düzeyleri arasında istatistiksel olarak anlamlı bir fark saptanmış ve kadınlarda ciddi düzeyde bağımlılık erkeklerden fazla tespit edilmiştir. Tip öğrencilerinde yapılan bazı çalışmalarda bizim çalışmamıza benzer şekilde kadınların erkeklerden daha fazla nomofobik oldukları bulunmuştur $(28,35,37)$. Kadınların erkeklerden daha fazla akıllı telefon bağımlısı olduğunu gösteren çalışmaların yanında erkeklerde fazla olduğunu gösteren çalışmalar olduğu gibi cinsiyet ile akıllı telefon bağımlılığı arasında fark olmadığını gösteren çalışmalar da

mevcuttur $(7,8,25,27,34,36,39,42,43)$.

Öğrencilerin sinıflarına göre akıllı telefon bağımlılık düzeyleri arasında farklı sonuçlar elde eden çalışmalar bulunmaktadır. Bizim çalışmamızda olduğu gibi öğrencilerin sınıfları ile akıllı telefon bağımlılık düzeyleri arasında fark saptanmamış çalışmalar $(36,39)$ olduğu gibi öğrencilerin sınıfları ile akıllı telefon 
bağımlılığı arasında anlamlı fark bulmuş çalışmalar da mevcuttur $(5,37,35)$.

Çalışmamızda akademik erteleme puan ortalaması $55.8 \pm 12.0$ 'dır. Aynı ölçeği kullanılarak tıp fakültesi öğrencilerinde yapılan çalışmada $(55,79 \pm 13,21) \quad$ ve öğretmen adaylarıyla yapılan çalışmadakine $(51.43 \pm 12.43)$ benzer puan ortalamaları bulunmuştur (44,45). Akademik erteleme ölçeğinin en yüksek puanın 95, en düşük puanının 19 olabileceği düşünüldüğünde lisans öğrencilerimizin orta düzeyde ertelemeci oldukları söylenebilir. Çalışmamızda cinsiyete göre akademik erteleme puanları arasında fark yoktur. Bazı çalışmalarda benzer şekilde bulunmuştur $(18,48,49)$. Ancak farklı sonuçlar içeren çalışmalarda mevcuttur (44-47). Bu çalışmada öğrencilerin akademik erteleme puanları okudukları sınıf seviyelerine göre anlamlı farklılık göstermektedir. Beşinci sınıf öğrencilerinin dördüncü sınıf öğrencilerine göre daha ertelemeci oldukları görülmüştür. Seyhun'un çalışmasında tıp fakültesinde 1. ve 5. sınıflar arasında anlamlı bir fark bulmuş ve en düşük erteleme puanın birinci en yüksek erteleme puanı beşinci sınıflarda olduğu gösterilmiştir (44). Çeri'nin çalışmasında birinci sınıfta okuyan öğrencilerin ikinci ve üçüncü sınıfta okuyan öğrencilere oranla daha fazla akademik erteleme davranışı gösterdikleri tespit edilmiştir (48). Aynı zamanda, dördüncü sınıfta okuyan öğrencilerin üçüncü sınıfta okuyan öğrencilere kıyasla daha fazla akademik erteleme davranışı göstermeye eğilimli oldukları gösterilmiştir. Kınık' ın çalışmasında ise fark saptanmamıştır (49).

Öğrencilerin nomofobi durumlarına göre de akademik erteleme puanları arasında fark tespit edilmiştir. Fark hafif nomofobik olanların akademik erteleme puanlarının orta ve ciddi düzeyde nomofobik olanlardan daha düşük olmasından kaynaklanmaktadır. Nomofobik olma durumu ilerledikçe öğrenciler akademik erteleme davranışı sergilemektedirler.

Bizim çalışmamızda nomofobinin akademik erteleme üzerinde pozitif yönlü; akademik Tıp Eğitimi Dünyası / Mayıs-Ağustos 2021 / Say1 61 ertelemenin de GANO üzerinde negatif yönlü etkisi olduğu görülmüştür. Nomofobinin GANO üzerinde negatif yönlü etkisi de görülmektedir. Yapılan tüm analizler birlikte incelendiğinde akademik ertelemenin GANO’yu düşürdüğü; nomofobinin doğrudan akademik ertelemeyi arttırırken dolaylı olarak da GANO’yu düşürdüğü gösterilmiştir. Sezer B. çalışmasında nomofobinin akademik başarı ile ilişkili olduğunu bulmuş ve akademik başarısı 50-60 olan öğrencilerin nomofobi puanlarının 81-90 ve 91-100 olan öğrencilerden farklı olduğunu göstermiştir (39). Arvind'in çalışmasında nomofobi puanlarının öğrencilerin akademik performanslarıyla ters ilişkili olduğu, yani artan nomofobi puanlarının akademik performansları düşürdüğü görülmüştür. Ahmed ile Anju'nun çalışması da nomofobinin devamsızlık, bozulmuş çalışma alışkanlığı, konsantre olamama, sık sık ders kaçırma ve derse geç gelme gibi nedenlerle akademik performans üzerinde ciddi bir etkiye sahip olduğunu ortaya konmuştur $(50,51)$.

\section{SONUÇ}

Akıllı telefon kullanımı gittikçe artan bir durumdur. Doğru kontrol edilmediği takdirde akıllı telefon kullanımı çok kritik bir sorun haline gelebilir. Öğrencilerimizin akıllı telefon kullanımlarının akılcı olmadığı çalışmanın sonuçlarından anlaşılmaktadır. $\mathrm{Bu}$ durumun önüne geçebilmek için öğrencilerimiz bilinçlendirilmeli ve farkındalık sağlanmalıdır. Tıp eğitimi müfredatı içine akıllı telefon kullanımının etkileri ve akılcı kullanıma ilişkin konular eklenebilir.

\section{KAYNAKLAR}

1. Yanık A, Batu M. Sorunlu Akıllı Telefon Kullanımı ve Öne Çıkan Psikopatolojilerin Sistematik Gözden Geçirilmesi. In: Mercan Y (Ed.). Multidisipliner Perspektiften Psikoloji. İksad yayınevi;2019.

2. Erdem H, Türen U, Kalkın G. Mobil 
Telefon Yoksunluğu Korkusu (Nomofobi) Yayılımı: Türkiye'den Üniversite Öğrencileri ve Kamu Çalışanları Örneklemi. Bilişim Teknolojileri Dergisi 2017;10(1):1-12.

3. Gökaliler E, Aybar A, Göker G. Bir Statü Tüketimi Göstergesi Olarak Iphone Markalı Akıllı Telefon Algısı: Üniversite Öğrencileri Üzerine Bir Araştırma. Selçuk Üniversitesi İletişim Fakültesi Akademik Dergisi 2011;7(1):36-48.

4. Bragazzi NL, Del Puente G. A Proposal for Including Nomophobia in The New DSM-V. Psychology Research And Behavior Management 2014; 7:155-160.

5. Prasad M, Patthi B, Singla A, Gupta R, Saha S, Kumar JK, Malhi R, Pandita V. Nomophobia: A Cross-sectional Study to Assess Mobile Phone Usage Among Dental Students. Journal of Clinical and Diagnostic Research 2017:11(2): ZC34-ZC39.

6. Akanferri AA, Aziale LK, Asampana I. An Empirical Study on Mobile Phone Usage Among Young Adults in Ghana: From the Viewpoint of University Students. Int J Comput Appl. 2014;98(5):15-21.

7. Minaz A, Çetinkaya Bozkurt Ö. Üniversite Öğrencilerinin Akıllı Telefon Bağımlılık Düzeylerinin ve Kullanım Amaçlarının Farklı Değişkenler Açısından İncelenmesi. Mehmet Akif Ersoy Üniversitesi Sosyal Bilimler Enstitüsü Dergisi 2017; 9(21):268-286.

8. Sharma N, Advani U, Sharma L, Jain M, Sharma K, Dixit AM. Pattern of Mobile Phone Usage Among Medical Students. Int J Acad Med. 2019; 5:118-23.

9. Yıldırım C, Şumuer E, Adnan M, Yıldırım S. A Growing Fear Prevalence of Nomophobia Among Turkish College Students. Information Development 2016;32(5):1322- 1331.

Tıp Eğitimi Dünyası / Mayıs-Ağustos 2021 / Say1 61
10. Steel P. The Nature of Procrastination: A Meta-Analytic and Theoretical Review of Quintessential Self-Regulatory Failure. Psychological Bulletin 2007;133(1):65-94.

11. Klassen RM, Krawchuk LL, Rajani S. Academic Procrastination of Undergraduates: Low Self-Efficacy to Self-Regulate Predicts Higher Levels of Procrastination. Contemporary Educational Psychology 2007; 33:915-931.

12. Lay CH. At Last, My Research Article on Procrastination, Journal Of Research in Personality 1986; z20(4):474-495.

13. Guzey M. Akademik Erteleme: Bir Öğrenci Klasiği. Türk Psikoloji Bülteni 2007;13 (41): 84-86.

14. Balk1s M, Duru E. Akademik Erteleme Davranışının Öğretmen Adayları Arasındaki Yaygınlığı, Demografik Özellikler ve Bireysel Tercihlerle İlişkisi. Eğitimde Kuram ve Uygulama 2009;5(1):18-32.

15. Uzun Özer B, Demir A, Ferrari JR. Exploring Academic Procrastination Among Turkish Students: Possible Gender Differences in Prevalence and Reasons. The Journal of Social Psychology 2009;149(2):241-257.

16. Bekleyen N. Understanding the Academic Procrastination Attitude of Language Learners in Turkish Universities. Educational Research and Reviews 2017;12(3):108-115.

17. Özer A, Altun E. Üniversite Öğrencilerinin Akademik Erteleme Nedenleri. Mehmet Akif Ersoy Üniversitesi Eğitim Fakültesi Dergisi 2011;11(21):45-72.

18. Demir Y, Kutlu M. İnternet Bağımlılığı, Akademik Erteleme ve Akademik Başarı Arasındaki İlişkiler. International Journal of Social Science 2017; 61:91-105. 
19. Yildırım C, Correia AP. Exploring the Dimensions of Nomophobia: Development, Validation of A Self-Reported Questionnaire. Computers in Human Behavior 2015; 49: 130137.

20. Çakıcı DÇ. Lise ve Üniversite Öğrencilerinde Genel Erteleme ve Akademik Erteleme Davranışının İncelenmesi. (Yüksek lisans tezi). Ankara Üniversitesi Eğitim Bilimleri Enstitüsü 2003, Ankara.

21. Toraman Ç, Özdemir HF, Koşan Aytuğ AM, Orakçı Ş. Relationships between Cognitive Flexibility, Perceived Quality of Faculty Life, Learning Approaches, and Academic Achievement. International Journal of Instruction 2020;13(1):85-100.

22. Sut Kahyaoğlu H, Kurt S, Uzal Ö, Özdilek S. Sağlık Bilimleri Fakültesi Öğrencilerinin Akıllı Telefon Bağımlılık Düzeylerinin Sosyal ve Eğitim Hayatına Etkisi. Euras J Fam Med 2016;5(1):13-19.

23. Baghianimoghadam MH, Shahbazi H, Masoodi Boroojeni D, Baghianimoghadam B. Attitude and Usage of Mobile Phone among Students in Yazd University of Medical Science. Iran Red Crescent Med J. 2013;15(8):752-4.

24. Siddiqi N, Jahan F, Moin F, Al-Shehhi F, Albalushi F. Excessive use of Mobile Phones by Medical Students: Should Precautions be Taken? Biomedical and Pharmacology Journal 2017;10(4):1631-1638.

25. Pavithra MB, Suwarna M, Mahadeva Murthy TS. A Study on Nomophobia- Mobile Phone Dependence, Among Students of a Medical College in Bangalore. Ntl $\mathrm{J}$ of Community Med 2015;6(3):340-344.

26. Ünal MH. Ankara Yıldırım Beyazıt Üniversitesi Tıp Fakültesi Öğrencilerinin Akıllı
Telefon Bağımlılık Düzeylerinin Belirlenmesi. Uzmanlık Tezi 2015. T.C. Sağlık Bakanlığı Yıldırım Beyazıt Üniversitesi Tıp Fakültesi Aile Hekimliği Anabilim Dalı.

27. Madhusudan M, Sudarshan P, Tv S, Gopi A, Fernandes S. Nomophobia and Its Determinants Among The Students of A Medical College in Kerala. International Journal of Medical Science and Public Health 2017; 6:1046-1049.

28. Sethia S, Melwani V, Melwani S, Priya A, Gupta M, Khan A. A Study to Assess The Degree of Nomophobia Among The Undergraduate Students of A Medical College in Bhopal. International Journal Of Community Medicine And Public Health 2018; 5(6): 24422445.

29. Yıldırım S, Kolcu G, Başaran Ö, Tamam İ. Smart Phone Addiction And Related Factors in First Class Students of A University Faculty of Medicine. Med J SDU 2019;26(4): 396-407.

30. Aman T. Shah N, Hussain A, Khan A, Asif S, Qazi1A. Effects Of Mobile Phone Use On The Social And Academic Performance Of Students Of A Public Sector Medical College In Khyber Pakhtunkhwa Pakıstan. KJMS 2015;8(1):99-103.

31. Rosen LD, Carrier LM, Cheever NA. Facebook and Texting Made Me Do It: MediaInduced Task-Switching While Studying. Computers in Human Behavior 2013;29(3): 948-958.

32. Pellowe EL, Cooper A, Mattingly BA. Are Smart Phones Inhibiting Smartness? Smart Phone Presence, Mobile Phone Anxiety, and Cognitive Performance. Undergraduate Journal of Psychology 2015;28(1): 20-25.

33. Nikhita CS, Jadhav PR, Ajinkya SA. Prevalence of Mobile Phone Dependence in 
Secondary School Adolescents. Journal of Clinical and Diagnostic Research 2015;9(11): 6-9.

34. Farooqui IA, Pore P, Gothankar J. Nomophobia: an Emerging İssue in Medical İnstitutions? J Ment Health. 2018;27(5):438441.

35. Mengi A Abhishek, S, Gupta V. An Institution-Based Study to Assess The Prevalence Of Nomophobia and Its Related Impact Among Medical Students in Southern Haryana,India. J Family Med Prim Care 2020;9(5):2303-2308.

36. Basu S, Garg S, Singh MM, Kohli C. Addiction-like Behavior Associated with Mobile Phone Usage among Medical Students in Delhi. Indian J Psychol Med. 2018; 40:44651.

37. Dasgupta P, Bhattacherjee S, Dasgupta S, Roy JK, Mukherjee A, Biswas R. Nomophobic Behaviors Among Smartphone Using Medical and Engineering Students in Two Colleges Of West Bengal. Indian J Public Health 2017; 61:199-204.

38. Davie N, Hilber T. Nomophobia: Is Smartphone Addiction a Genuine Risk For Mobile Learning? 13th International Conference Mobile Learning 2017. p:100-104.

39. Sezer B, Atılgan Çiftçi SB. Akıllı Telefon Kullanımının Karanlık Tarafi (Nomofobi): Endişelenmemize Gerek Var Mı? Tıp Eğitimi Dünyası 2019;18(54): 30-43.

40. Okuyan Birimoğlu C, Güner Döner P, Güneş Uslusoy S. Hemşirelik ve Tip Fakültesi Öğrencilerinin Nomofobi Düzeylerinin Belirlenmesi. Gümüşhane Üniversitesi Sağlık Bilimleri Dergisi 2019;8(4):372-382.

41. Hoşgör H, Tandoğan Ö, Gündüz Hoşgör D. Nomofobinin Günlük Akıllı Telefon Kullanım
Süresi Ve Okul Başarısı Üzerindeki Etkisi: Sağlık Personeli Adayları Örneği. The Journal of Academic Social Science 2017; 5(46):573595.

42. Özdemir B, Cakir O, Hussain Irshad. Prevalence of Nomophobia among University Students: A Comparative Study of Pakistani and Turkish Undergraduate Students. EURASIA Journal of Mathematics, Science and Technology Education 2018; 14(4):1519-1532.

43. Gürbüz IB, Ozkan G. What is Your Level of Nomophobia? An Investigation of Prevalence and Level of Nomophobia Among Young People in Turkey. Community Mental Health Journal 2020; 56:814-822.

44. Seyhun S, Özçelik S, Yabacı A, Bezmialem Vakıf Üniversitesi Öğrencilerinin Akademik Erteleme Davranışlarının İncelenmesi, XI. Ulusal Tıp Eğitimi Çevrimiçi Kongresi, İstanbul, Türkiye, 12 -14 Ekim 2020, ss.1-2.

45. Gültekin S, Gürer GT. Formasyon Öğretmen Adaylarının Akademik Erteleme Davranışları ile Akademik Özyeterlik Düzeyleri İlişkisi. International Journal of Computers in Education (IJCE) 2018;1(1):49-64.

46. Balkıs M, Erdinç D. Gender Differences in The Relationship Between Academic Procrastination, Satifaction with Academic Life and Academic Performance. Electronic Journal of Research in Educational Psychology 2017;15(1):105-125.

47. Bulut R, Ocak G. Öğretmen Adaylarının Akademik Erteleme Davranışlarını Etkileyen Etmenler. E-Uluslar arası Eğitim Araştırmaları Dergisi 2017;8(2):75-90.

48. Çeri B, Çavuşoğlu C, Gürol M. Üniversite Öğrencilerinin Akademik Erteleme Düzeylerinin İncelenmesi. International Journal of Social Science 2015; 34:385-394. 
49. Kınık Ö, Odacı H. Üniversite Öğrencilerinde Akademik Erteleme Davranışı: Bazı Bireysel ve Çevresel Değişkenler Bir Etken Olabilir mi? Yükseköğretim ve Bilim Dergisi 2020; 10(1): 183-192.

50. Ahmed S, Pokhrel N, Roy S, Samuel AJ. Impact of Nomophobia: A Nondrug Addiction Among Studentsof Physiotherapy Course Using an Online Cross-Sectional Survey. Indian J Psychiatry 2019; 61:77-80.

51. Anju PT, Aswathy KS, Athira S, Athulya N. Mobile Phone Dependence and Sleep Quality Among Undergraduate Students. Indian J Forensic Med Toxicol. 2019; 13:11-5. 